\title{
LOS "HIJOS DEL PECADO": UNA APROXIMACIÓN A LA CASA DE EXPÓSITOS DE MÁlAGA EN LA SEGUNDA MITAD DE LA CENTURIA ILUSTRADA
}

\author{
M. ${ }^{\mathrm{a}}$ Del Pilar Jiménez GutiérRez*
}

\begin{abstract}
RESUMEN
El trabajo que aquí se presenta es el estudio de la Casa de Expósitos de Málaga y con él se pretende dar a conocer la historia de la institución que, desde 1573 hasta 1988, acogía a los niños abandonados de la ciudad y provincia. Está centrado en el marco cronológico del reinado de Carlos III debido a que en dicho periodo se adquirió una cierta preocupación por este colectivo. Se analiza la situación de los menores y el motivo de los abandonos a través de los Libros de Matrículas del establecimiento a la vez que se realiza una evaluación de la legislación promulgada por el monarca que permitirá hacer una valoración global del fenómeno en la ciudad y establecer las conclusiones de la investigación.
\end{abstract}

PALABRAS CLAVE: expósito, casa cuna, inclusa, amas de cría, torno

Enviado: 15-9-2019

Aceptado: 15-1-2020

*mpilarjimenezgutierrez@gmail.com 


\title{
"CHILDREN FROM SIN": AN APPROXIMATION TO THE FOUNDLING HOUSE IN MÁLAGA DURING THE SECOND HALF OF THE ILLUSTRATED CENTURY
}

\author{
M. ${ }^{\mathrm{a}}$ Del Pilar Jiménez GutiérRez*
}

\begin{abstract}
With the presented work, which is about the study of the Foundling House in Málaga, we intend to show the history of this institution, where abandoned children in the city and the province were taken in from 1573 and 1988. For that end, we will focus on the chronological framework of the reign of Carlos III, since certain degree of concern for outcasts and, among them, for foundlings as the most vulnerable group, became relevant during that period. We will analyse the situation of minors and the reasons for child abandonment through the Registration Books of the institution, as well as we will evaluate the legislation enacted by the monarch, which will allow us to make a global assessment of the phenomenon in the city to establish the conclusions for our research.
\end{abstract}

KEYWORDS: foundling, Crib House, Foundling hospital, wet nurses, lathe

Enviado: 15-9-2019

Aceptado: 15-1-2020

*mpilarjimenezgutierrez@gmail.com 
En 16 febrero 1756 entre oración y Animas entraron por el Torno un niño embuelto en un trapo blanco hecho pedazos; y en este dia 17 del mismo mes, se Baptizó en el Sagrario con el nombre de Juan de la Cruz ${ }^{1}$.

Desde mediados de los años setenta del pasado siglo y fruto del giro social experimentado por las investigaciones desarrolladas en el marco de la escuela francesa de Annales, la producción historiográfica adquirió una mayor preocupación por el estudio de los estratos más bajos de la sociedad frente al tradicional interés por las élites. A raíz de ello el análisis y estudio de la infancia tomó inicio, aunque enfocado en los expósitos y las instituciones que los acogieron ${ }^{2}$. En España hasta la llegada de los ochenta y concretamente a raíz de la publicación de El niño y la vida familiar en el Antiguo Régimen de Philippe Ariès no se produjo un auge en las investigaciones centradas en estos niños y las instituciones asistenciales, ofreciendo como resultado un abultado número de publicaciones de ámbito local y "de corte demográfico-cuantitativo de la exposición institucionalizada como protagonista", 3 , que nos aportan el conocimiento y la realidad de este grupo social desde una visión de la historia social, demográfica y de las mentalidades ${ }^{4}$.

Sin embargo, encontramos un vacío respecto al Hospital de San José, Casa de Expósitos de la ciudad de Málaga, por lo que hemos decidido realizar la siguiente investigación pese a que recientemente el estudio de los ciclos vitales está dirigido mayoritariamente a las trayectorias de estos niños, con un mayor interés hacia la juventud y su papel en la sociedad, sirvan como ejemplo los trabajos realizados por Blanco Carrasco, García González y García Fernández, entre otros ${ }^{5}$.

1. Archivo Diputación Provincial de Málaga (ADPM), Libro de Matrículas de Expósitos (L.), 0016, fol. 192r, matrícula (mat.) 222.

2. M. G. Cava López (2000), 15.

3. M. G. Cava López (2004), 751-753.

4. Como ya se ha comentado la relación de investigaciones es considerable, pero caben destacar, entre otras, las siguientes: A. Eiras Roel (1967); P. Demerson (1972); L. C. Álvarez Santaló (1977); (1978); (1980); A. Domínguez Ortiz (1983); F. Chacón, R. Fresneda y R. Elgarrista (1986); E. Gómez Martínez (1987); M. Fernández Ugarte (1988); M. Vallecillo Capilla (1990); J. M. Santana Pérez (1993); A. Tarifa Fernández (1994); T. Gómez Ruiz (1997); M. P. de la Fuente Galán (1997); (1999) 130.

5. Vide J. P. Blanco Carrasco, M. García Fernández y F. Olival (coords), (2019); F. García GonzÁlez (2007). 
Nuestro estudio está centrado en el siglo XVIII debido a que, con la llegada de la Ilustración, se produjeron cambios en la forma de pensar en las altas esferas eruditas y, por extensión, en el ideario político del gobierno dieciochesco a causa de la evolución en el pensamiento de Occidente, fruto, como apunta Cunningham, de la progresiva secularización de gran parte de la sociedad ${ }^{6}$, adquiriéndose una cierta preocupación por los marginados y, dentro de ellos, por el niño expósito como el sector más indefenso de dicho colectivo.

Podríamos decir que tras la publicación de Emile o De la Educación de Jean-Jacques Rousseau, en 1762, este interés se vio acrecentado y los tratadistas de la época vertieron ríos de tinta denunciando el mal estado en el que se encontraban las inclusas, pidiendo que se pusiera remedio a la miserable vida que arrastraban estos menores. Dentro de los escritos producidos en el territorio hispánico caben destacar El Tratado de remedio de los pobres, de Alejandro de Alés; El Discurso acerca de la situación y división interior de los hospicios con respecto a su salubridad, publicado por Gaspar Melchor de Jovellanos en el año 1778; Destrucción y conservación de los expositos: idea de la perfección de este ramo de policia: modo breve de poblar la España y testamento de Antonio de Bilbao y Tratado del Socorro de los Pobres de Juan Luis Vives, publicado en 1526 pero reeditado en el siglo XVIII, adquiriendo gran relevancia ${ }^{7}$.

A consecuencia de este cambio de mentalidad la idea caritativa cristiana con respecto a la pobreza fue reemplazada por un práctico altruismo desencadenando con ello cierta competencia a la vez que cooperación entre las autoridades cívicas y religiosas, favoreciendo la ejecución de centros asistenciales dedicados a estos menores ${ }^{8}$. El valor adquirido por la figura del niño fue representado en las artes pictóricas, como es posible comprobar en la desigualdad existente entre los retratos de la infanta Margarita Francisca (c. 1610) y el de Manuela Isidra Téllez-Girón (1797). Si bien es cierto que durante el Siglo de Oro la plasmación de los niños fue usual, la diferencia observable en el XVIII es el tratamiento que se les da.

No obstante, fue la iglesia quien monopolizó el auxilio social a lo largo de la modernidad a través de la misericordia y la caridad cristiana, ya que mediante las dádivas los pudientes podían ser absueltos de sus culpas, lo

6. B. Alcubierre Moya (2018), 23-24.

7. Citados por I. Zavala (1978) 44. y A. Alvar Ezquerra, y A. Domínguez Ortiz (2005), 277.

8. B. Alcubierre Moya (2018), 25-26. 
que llevó a la creación de instituciones benéficas promovidas por cofradías y obras pías 9 . Tampoco podemos olvidar a los gremios que tuvieron un papel bastante importante ya que entre sus funciones asumieron la creación de cofradías y hospitales dedicados a la asistencia ${ }^{10}$, ejemplo de ello es el Hospital de San José, Casa de Expósitos de Málaga, que subsistían mediante limosnas, mandas testamentarias y herencias, como apreciamos en el testamento de Leandro Fernández de Moratín, para la Inclusa de Madrid, fechado el 14 de mayo de 1812:

Quiero que doña María Fernández de Moratín sea usufructuaria durante su vida de las casas que me corresponden en esta Corte, la una Calle de Foncarral (sic) número ocho, manzana trescientas cuarenta y cinco, y la otra Calle de San Juan Bautista número once, manzana trescientos quince, y que después pasen a propiedad de la Casa de Niños Expósitos de la misma ${ }^{11}$.

El hecho de centrarnos en el reinado de Carlos III es debido a que en su gobierno se dictaron leyes y normativas específicas para las Casas de Pobres y Niños Expósitos, promulgándose la primera de ellas en 1780, y dice así:

... estas casas se deberán construir, o proporcionar si estuviesen hechas, con respecto a la extensión de la provincia, y número de pobres que se calcule podrá recogerse en ella, y con reflexión a las fábricas que convenga establecer, (...), atendidos los materiales que produce cada país, por lo que no puede darse punto fixo ni determinada regla; pero sí puede decirse que en todas ellas deberá haber dormitorios, laboratorios, y demas oficinas enteramente separadas, y sin comunicacion para ambos sexos ${ }^{12}$.

Los objetivos de nuestro trabajo son, en primer lugar, valorar la efectividad de la legislación promulgada por el monarca en Málaga y, para ello analizamos el quinquenio anterior (1754-1758) y último (1784-1788) de dicho reinado y, en segundo lugar, dar a conocer la situación de estos infantes en la ciudad, puesto que los resultados genéricos, obtenidos en los estudios realizados para las distintas Cunas de nuestro país, son susceptibles de ser aplicados al Hospital de San José, Casa de Expósitos de Málaga.

9. M. LeÓN Vegas (2013), 283-284.

10. S. Villas Tinoco (1982), 174.

11. Citado por F. Hidalgo Fernández, (2019), 155.

12. Novísima Recopilación de las Leyes de España (1805), 695. 
Para ello se han cuantificado y analizado las inscripciones correspondientes al periodo mencionado anotadas en los Libros de Matrícula 0016 al 0019 del establecimiento.

La fuente principal de nuestra investigación ha sido el Archivo de la Diputación Provincial de Málaga, donde se custodian 385 Libros de Matrículas de Expósitos que comprenden desde 1640 a $1981^{13}$. En cambio no se conservan los Libros de Salida de los incluseros ni la documentación referente a la administración, financiación y personal de la casa en la época que nos ocupa, hallándose la concerniente a la Obra Pía de Niños de la Providencia y Escuela General de Pobres ${ }^{14}$, lo que nos hace pensar que pudo haber desaparecido en los desvalijamientos que sufrió el archivo en el año 1868 o en la quema del edificio de la Aduana en 1922, ya que este se hallaba en dicho inmueble ${ }^{15}$.

\section{EL HOSPITAL DE SAN JOSÉ, CASA DE EXPÓSITOS}

Como decía Tomás de Montalvo (1701): "El fin principal de los Hospitales de Expósitos es el logro de las almas de estos míseros infantes, cuya primera diligencia es el que reciban el Bautismo, donde se numeran los hombres por hijos de Dios"16.

El nacimiento de la Casa de Expósitos de Málaga lo hallamos en 1573, siendo obispo de la ciudad don Francisco Blanco de Salcedo, cuando el gremio de carpinteros decidió nombrar a san José como su patrón, dándole culto en la parroquia de los Santos Mártires, a la vez que tomó la iniciativa de dar cobijo a los niños expósitos recogiéndolos en el Hospital de Convalecientes, fundado en 1571 por doña Isabel Dalvo, esposa del regidor malagueño Contador de Baena ${ }^{17}$.

13. En los Libros de Matrículas hallamos las inscripciones de acogidos cronológicamente, con todas las particularidades concernientes a la entrada y en algunas también encontramos las circunstancias que rodearon a la salida de los menores de la institución. Los Libros están distribuidos de la siguiente manera: 130 pertenecientes a la casa central de Málaga a falta de los siguientes años: 1846, 1872, 1882-1884, 1894, 1946-1955; 64 de la Hijuela de Antequera: 1848-1913, faltando desde 1864-1870; 64 de la Hijuela de Marbella: 1848-1913; 64 de la Hijuela de Ronda: 1864-1913 y 63 de la Hijuela de Vélez-Málaga: 1847-1913.

14. Vide M. Reder Gadow (1985), 405-415.

15. C. Sanchidrián Blanco y F. Martín ZúNiga (2009), 123-137.

16. Citado por V. Pérez Moreda (2005), 23.

17. C. García de la Leña (1793), 12. 
Para poder llevar a cabo dicho fin, expusieron a su santidad Gregorio XIII el anhelo de crear una cofradía, y en diciembre del mismo año, el papa remitió una bula en la que les concedió licencia para su creación y establecimiento en la iglesia que ellos deseasen, cuyos estatutos debían ser aprobados por el obispo ${ }^{18}$.

La bula fue obedecida por el prelado de la ciudad, Francisco Pacheco y Córdoba, el día 20 de septiembre de 1576, creándose la cofradía y aprobando sus constituciones el 14 de marzo de 1606, que fueron firmadas por su sucesor Juan Alonso Moscoso. En ellas no se elegía ninguna iglesia por lo que se siguió venerando a san José en la parroquia de los Mártires y recogiéndose a los niños en dicho Hospital, bajo el cuidado de una mujer a la que pasaban una remuneración ${ }^{19}$.

Posteriormente a esta aprobación, aunque en ninguno de sus capítulos se mencionaba a los expósitos, los carpinteros determinaron construir una ermita para adorar a su patrono y una casa-hospital donde asilar a los niños. Dichas obras se comenzaron en una parcela colindante al Hospital de Convalecientes, pero, debido a problemas económicos, el obispo tuvo que intervenir para que se finalizasen ${ }^{20}$. La casa-hospital fue fundada bajo la advocación del santo patrón con el nombre de "Hospital de San José, Casa de Expósitos", donde fueron trasladados los niños que se encontraban en el Hospital de Convalecientes ${ }^{21}$, comenzando a funcionar en el mes de noviembre del año 1640 como comprobamos en la siguiente inscripción correspondiente al primer Libro de Matrículas ${ }^{22}$.

Desde aqui se comiençan a escribir las criaturas que el Ldo. Antonio Godino hallo en la cuna de los niños expositos que estaba en los conbalecientes desde primero de nobiembre de 1640 años y las que se ban echando los años en adelante, las amas que los an criado, lo que an hecho de costas, los que sean prohijado los que sean muerto y los que viuen y el paradero que todos antenido y tendran desde el dicho día de nobiembre año de 1640 en adelante ${ }^{23}$.

18. Ibidem, 14.

19. Ibidem, 133.

20. Ibidem, 133-135.

21. ADPM, Patrimonio. Guía de Fondos y Secciones. Sección Beneficencia. Fondo Diputación Provincial de Málaga [en línea]. URL: http://www.malaga.es/archivo (consulta: 10-2-2018).

22. En la fecha del traslado de los niños del Hospital de Convalecientes a la Casa Hospital encontramos diferencia entre la que nos da García de la Leña, pues dice que fueron trasladados en julio de 1645 y la anotada en el Libro 0001 de Matriculas es noviembre de 1640 , por lo que damos como cierta esta última.

23. ADPM, L. 0001, fol. 2r. 


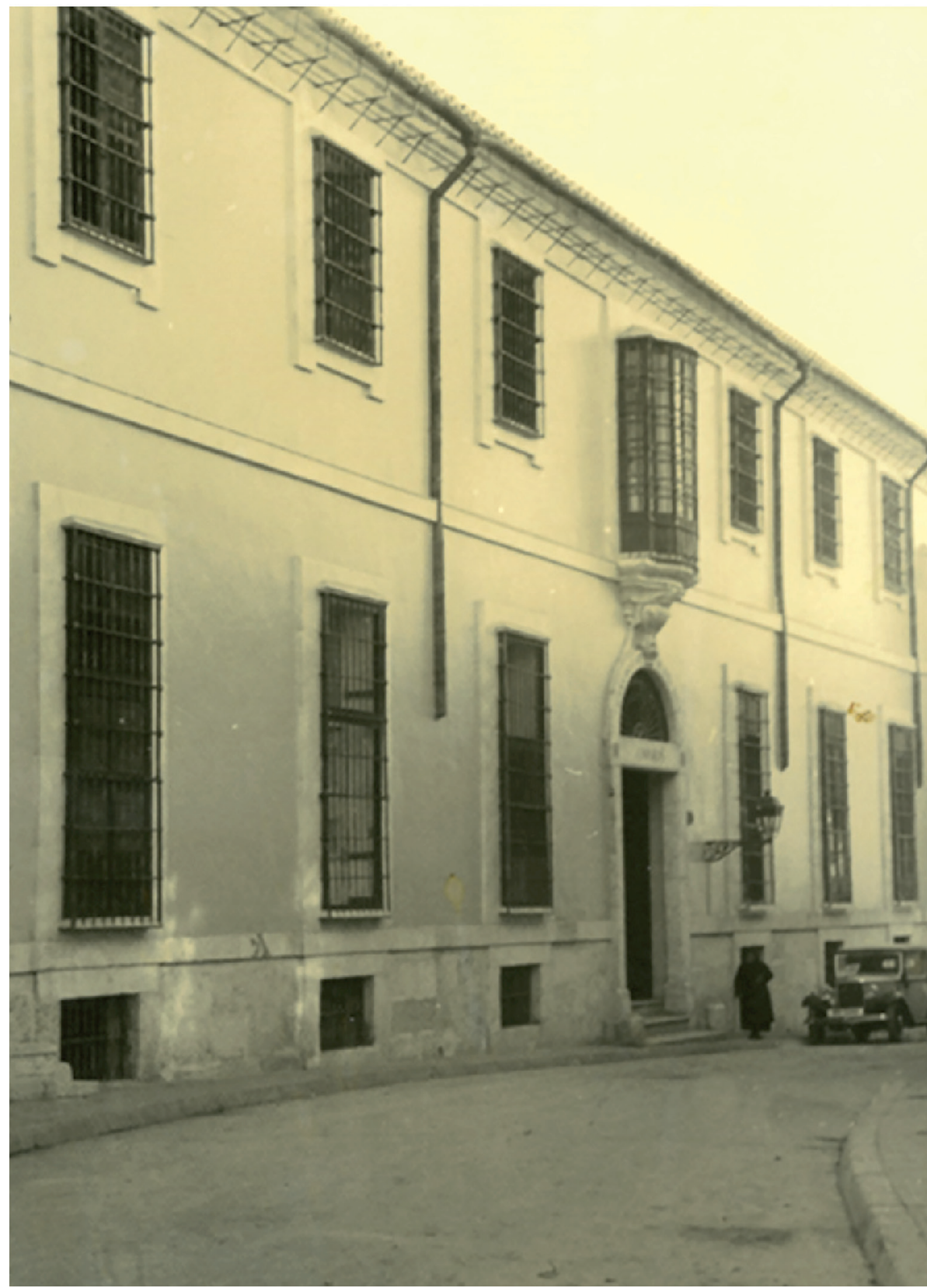

Imagen 1. Casa de Expósitos 1938.

Fachada principal reformada del edificio situado en calle Parras.

Fuente: http://www.malaga.es/archivo 
Una vez que la hermandad había trasladado su sede a la nueva ermita acordaron dar culto a san José en ella y ocuparse de los expósitos, como habían prometido, y para lo que fue concedida la bula. Pero ello no fue llevado a cabo y la jerarquía de la iglesia tomó cartas en el asunto hasta tal punto que el obispo Antonio Piñahermosa (1659-1664) se hizo cargo de la manutención económica de los menores ${ }^{24}$.

Debido a que los estatutos más antiguos conservados son de 1901 y la documentación referente al gobierno y personal de la Casa de Expósitos comienza en 1869, es imposible determinar exactamente su financiación en el periodo que estudiamos, aunque podemos asegurar, siguiendo a autores coetáneos, que se mantendría con las donaciones del prelado, particulares y las recogidas por un limosnero; los beneficios de los censos impuestos por el Cabildo; y "la herencia que le dexo de todo su caudal Don Sebastian de Arriola, Teniente General de Artilleria"25.

La Casa-Hospital sobrevivía a duras penas y a comienzos del siglo XVIII estuvo a punto de cerrar, pero su clausura pudo evitarse gracias a las donaciones y legados realizados por fray Manuel de Santo Tomás y Mendoza (1714-1717), obispo de Málaga, la primera de quinientos ducados, siguiendo con una renta mensual de trescientos reales para manutención y doscientos ducados anuales para vestir a los infantes ${ }^{26}$. La institución continuó subsistiendo a base de limosnas, censos y mandas testamentarias, como se puede comprobar en las escrituras testamentarias de protocolos notariales, hasta que la Junta Municipal en el XIX se hizo cargo de ella y, a partir de este momento los cambios de nombre y emplazamiento fueron recurrentes, trasladando su ubicación al exconvento de Santo Domingo en 1840 y, denominándose Casa de Maternidad, lugar donde se encontraban Mendicidad y Socorro.

En 1857 fue trasladada a un establecimiento que había pertenecido a los Niños de la Providencia, sito entre las calles Ollerías y Parras permaneciendo en este lugar hasta 1952, conociéndose como Casa-Cuna Hogar Provincial de San José, aunque durante los años 30-40 del pasado siglo cambió su nombre por el de Casa de la Infancia. A pesar de ello esta inclusa que, popularmente es conocida como la Gota de Leche, siguió manteniendo sus servicios hasta 1988 cuando pasó a depender de la Junta de Andalucía bajo la denominación de Centro Básico de Acogida ${ }^{27}$.

24. C. García de la Leña (1793), 165.

25. Ibidem, 135.

26. Ibidem, 165-237.

27. ADPM, Patrimonio. Guía de Fondos y Secciones. Sección Beneficencia. Fondo Diputación Provincial de Málaga [en línea]. URL: http://www.malaga.es/archivo (consulta: 10/08/2019). 
En cuanto a las dependencias y personal de la institución, en la época que nos ocupa, suponemos que serían similares a las de otras inclusas del territorio hispánico, regidas bajo unas mismas leyes. Los habitáculos de la casa estarían compuestos por un cuarto-torno separado del resto de las estancias con una puerta, cuya llave la tendría el ama que estuviese de guardia; una sala de destete para las amas de cría internas y los menores hasta los dieciocho meses, pues a partir de esa edad pasaban a habitaciones separadas por sexo; un dormitorio para el administrador; cocina con despensa; cuarto para el aseo y ropero. El personal que se ocupaba del establecimiento se diferenciaría según su condición de interno o externo, entre los primeros encontraríamos un rector; un ama mayor; las amas de cría internas cuyo número oscilaba entre dos y cuatro; y entre los externos las amas encargadas de criar a los expósitos en sus casas; una cocinera; una lavandera y una limpiadora ${ }^{28}$.

A pesar de no manejar la documentación administrativa de la Cuna podemos asegurar que en 1771 a las amas externas se les pagaba entre once o doce reales mensuales por la crianza de un menor, tal como aparece en la siguiente declaración jurada:

Parroquia del Sagrario

$\dagger$

Declaracion Jurada que Yo Phelipa De Cazas vezina de esta Ciudad hago en virtud De lo mandado por S. M. y Bando publicado para el establecimiento de la unica contribución en esta forma. //

Primeramente Declaro soy de edad de 37 años Viuda: tengo hijos. a Maria Martin De 13 años. Juan Martin de 11 años. Gertrudis De 9 años. Estoi criando Dos Niños de la Cuna./

Vivo en Casa que Administra Don Juan Mexciel, la que tengo arrendada a Distintos Vessinos sus cuartos, y solo Avito uno que por ser el mas inferior, y con lo que pagan los vecinos salgo de valde./

Mi Alimento y el De mis hijos se sobstiene con 23 reales mensuales que me dan por los dichos Niños de la Cuna, y con alguna otra limosna que me quieran hacer./

Cuia Relazion es cierta y verídica y asi lo juro por Dios y esta $\uparrow$ y por no saber firmar lo hiso,

Juan de Cazas

Rúbrica ${ }^{29}$.

28. M. del P. de la Fuente Galán (1999), 121-123.

29. Archivo Municipal de Málaga (AMM), Padrón de contribuyentes de 1771, caja 442 carpeta 19 , s. f. 


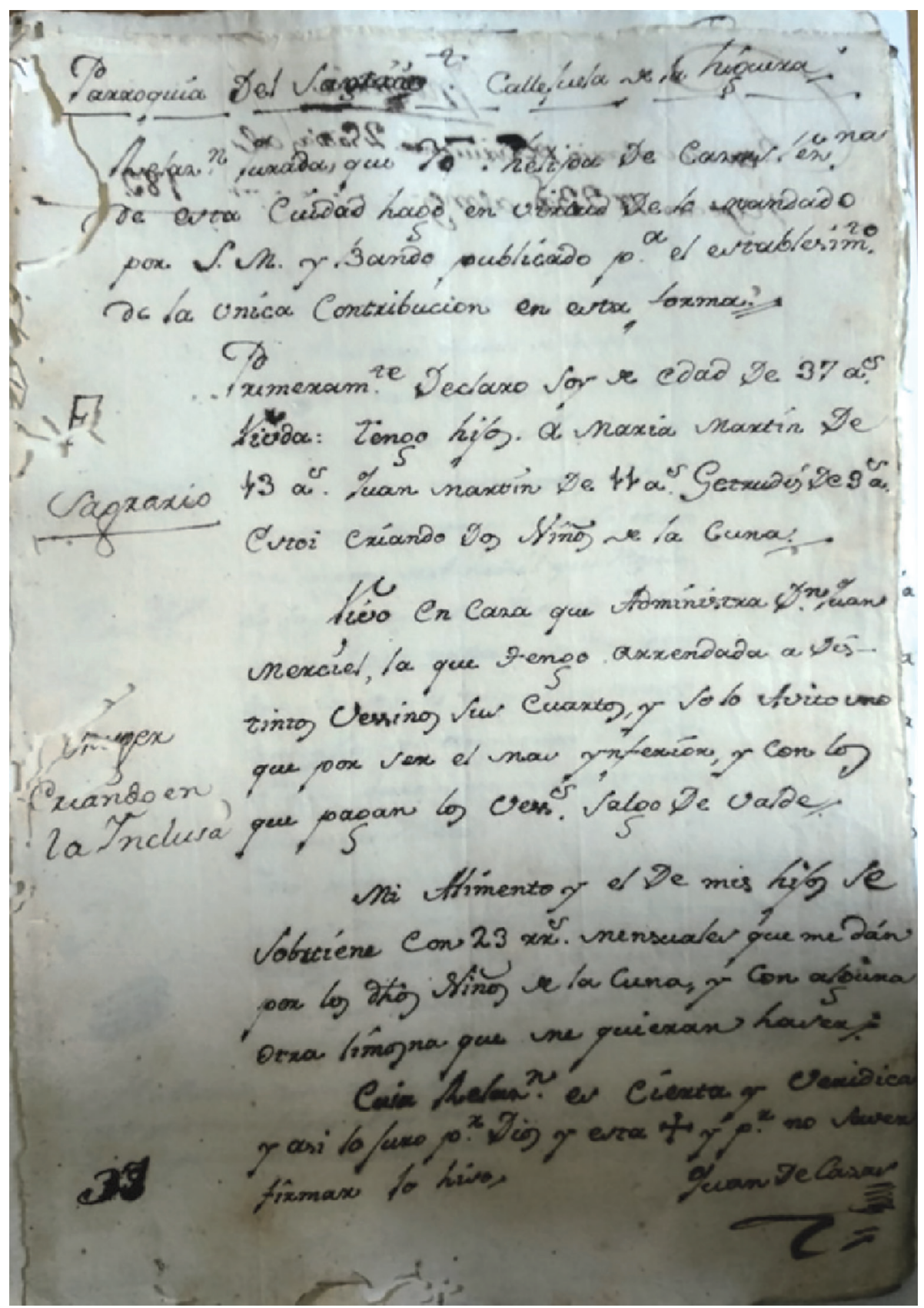

Imagen 2. Declaración jurada de mujer criando en la inclusa.

Fuente: AMM, Padrón de contribuyentes de 1771. 


\section{EL DEVENIR DE LOS EXPÓSITOS}

Es imposible determinar desde cuando existe esta práctica, pues ya la mitología griega habla del abandono de menores en el monte Parnaso y, presumiblemente, también existiría en la antigua Roma debido al poder absoluto que tenía el paterfamilias pudiendo decidir entre la vida y la muerte del hijo. Aunque sí podemos afirmar su presencia en la época imperial, puesto que los Severo (siglos II-III d. C.) dictaron normativas impidiendo el repudio de los vástagos. Sin embargo, a pesar de las muchas leyes promulgadas a lo largo de la historia prohibiendo el abandono de los niños, la exposición, por infinidad de motivos, ha llegado hasta nuestros días ${ }^{30}$.

Estos pequeños, en la época que nos ocupa, eran abandonados por diferentes razones y no solo tendríamos que responsabilizar de ello a sus progenitores sino más bien al contexto social en general, debido a que obligaba a vivir dentro de unas normas morales muy rígidas y aquellos que las transgredían se veían abocados al rechazo y marginalidad. Es pues una cuestión que no se ceñía solamente a la familia, sino que repercutía en toda la comunidad: estudiar el motivo que llevó a una persona al abandono supone, por lo tanto, analizar al colectivo que la obligó a ello.

A la hora de indagar las causas por las que estos menores son repudiados acudimos a las cédulas que portaban ${ }^{31}$, aunque no siempre es posible porque no todos llegaban con ellas. Debido al pensamiento del Antiguo Régimen es muy probable que muchos padres mintieran en el momento de la renuncia, ya que si pudiésemos examinar cada caso en particular comprobaríamos que el número de expósitos por ser ilegítimos es muy superior a los repudios por motivos económicos. Abandonar a un menor para que no muriese de hambre estaba totalmente aceptado y a la vez lo liberaba de la mácula de la ilegitimidad, ya que la mayoría de los estudiosos reconocen que para la sociedad de la época lo más importante fue la conservación de la honra familiar mediante la virtud de la mujer ${ }^{32}$.

30. Vide J. L. Sevilla Bujalance (2001).

31. Trozo de papel que a veces acompañaba al expósito, regularmente iba metido entre las vestiduras y en ellas se especificaban las causas del abandono, el nombre que se debía poner al menor, el nombre de la parroquia en el caso que estuviese bautizado y si había intención de recogerlo más adelante, podemos decir que eran el certificado de identidad de estos niños.

32. M. Fernández Ugarte (1988), 85-86. 


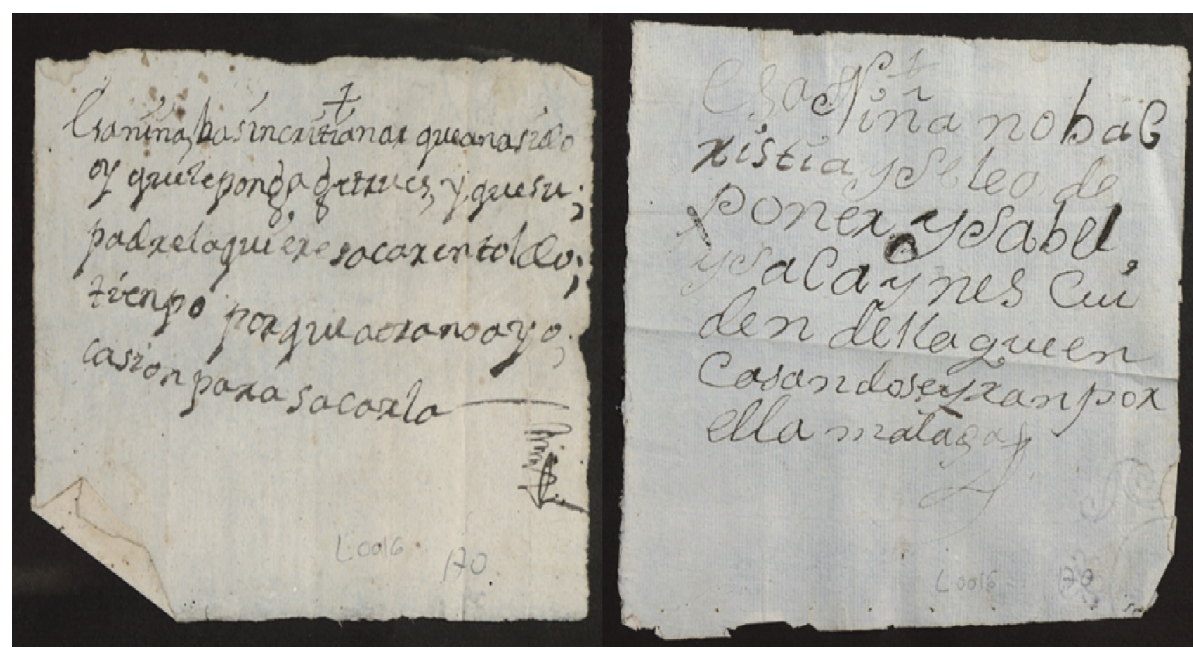

Imágenes 3 y 4 . Cédulas que acompañaban al expósito con la intención de recogerlo en un futuro.

Fuente: ADPM, L. 0016 hojas sueltas entre los fols. 169v y 170r.

Un gran número de investigadores aseveran que no es posible señalar el móvil o motivo por el que unos padres renunciaban a un hijo, ya que son un cúmulo de ellos y es imposible precisar en qué proporción influyeron unos sobre los otros. Aunque no es arriesgado afirmar que los abandonos se centraron en dos causas que, en la totalidad de los casos, se superponen como son el repudio al bastardo y la indigencia en la que vivía la mayor parte de la comunidad ${ }^{33}$.

Habitualmente llegaban a la Cuna de noche y la exposición se realizaba poniendo con el más absoluto de los secretos al menor en el torno, lo que además facilitaba que dicha persona quedara en el anonimato ${ }^{34}$. Otra forma de preservar la honra de la familia era enviar a los niños a través de la comadre del barrio ${ }^{35}$.

33. M. J. Pérez Álvarez (1988), 366-367; J. C. Cobo Barquín, R. Hernández Mejía y L. V. SÁnchez Fernández (2013), 135.

34. E. Gómez Martínez (1987), 158.

35. En la actualidad la llamaríamos comadrona o matrona. Covarrubias en su diccionario de 1611 dice: COMADRE, vale madre juntamente, con la que lo es verdadera: y llamamos comadre a la que ayuda a parir, que cura de la madre, y de la criatura. Esta por otro nombre se llama partera. Real Academia Española. Nuevo Tesoro Lexicográfico (NTLLE). U 1780. URL: http://ntlle.rae.es (consulta: 8/5/2019). NTLLE RAE COV M 1611, 450.2-451.1. 
En 14 Diziembre 757. ymviò a este Hospital la comadre Anica dos Niños, diciendo que eran Mellizos; venían en Carnes; y en este mismo dia se Baptizaron en el Sagrario, con los nombres, el primero, de Pasqual; y el segundo, de Francisco de Borja. Se pusieron las fees (sic), en el Legajo n. ${ }^{\circ}$ 147 y $148^{36}$.

Tal como es de suponer, los que procedían del medio rural eran entregados en la Cuna de día, llegando en muy malas condiciones ya que habían sido abandonados en la puerta de la iglesia o algún lugar público la noche anterior. Generalmente estas criaturas habían pasado horas a la intemperie, como decía el conde de Cabarrús “expuestas á la inclemencia de los elementos, ó á las injurias de los animales" 37 , y sufrido un viaje largo y bastante dificultoso por el mal estado de los caminos hasta la capital, metidos en un cesto o una espuerta. No es de extrañar, por tanto, que la mayoría murieran en el traslado, una circunstancia agravada por producirse en los primeros días de la vida del menor, como bien nos manifiesta un coetáneo "Ojalá los portadores no los trataran tan mal que luego se mueran, de que me consta" 38 .

Excepto raras excepciones, el expósito era depositado en el torno "en carnes" o con vestimentas muy pobres, normalmente compuestas de "Harambeles o jarambeles ${ }^{39}$, faja ${ }^{40}$, pañal con farfalá ${ }^{41}$, batista de Holanda

36. ADPM, L. 0017, fol. 041v, mats. 147 y 148.

37. Conde de Cabarrús (1820), 32.

38. M. Fernández Ugarte (1988), 104.

39. Arambel: Del ár. hisp. alhánbal 'especie de poyal o tapiz para estrados', y este del ár. clás. hanbal 'pelliza usada'. 1. m. Colgadura de paños unidos o separados que se emplea para adorno o cobertura. 2. m. Andrajo o trapo que cuelga del vestido. RAE (2001).

40. "FAJA: s. f. La cinta con que se ciñe y rodea el cuerpo, especialmente en los niños, que se las ponen con muchas vueltas para asegurar las mantillas que les sirven de vestidura y abrigo". E. Gómez Martínez (1987), 179.

41. Farfalá: El Diccionario de Autoridades nos remite a la siguiente palabra: "FalBALA. s. m. Adorno compuesto de una tira de tafetán, o de otra tela que rodea las basquiñas y briales de las mugeres, toda alechugada y cosida por el canto superior, y suelta por el inferior: y se suelen echar no solo uno sino dos, tres, y aun quatro. Tambien se llaman assí las cenefas de cortinas puestas en la misma disposición. El uso de este adorno es moderno en España, y la voz tomada del Felbalo Húngaro. Oy comunmente se dice Farfalá. Latín. Instita, ae”. Diccionario de Autoridades, tomo III (1732), 709. 
u Olan ${ }^{42}$, mantilla de bayeta ${ }^{43}$, pañal de creguela ${ }^{44}$ " y todo con la coletilla "muy viejo o hecho pedazos".

Sin embargo, había niños que llegaban con toda la ropa nueva y de calidad, posiblemente procedían de clases acomodadas o en un principio no había intención de exponerlos ${ }^{45}$, sirva como ejemplo el caso de Francisco Javier:

En 2 Septiembre 1756 a las tres de la tarde entraron por el Torno un Niño embuelto en una camisa de Noviciate nueva, con gorguera de Vanda fina ancha, y nueva: Un Pañal de Crea fina nuevo: Rebozo de Noviciate nuevo, con su vanda fina nueva: Una Mantilla de Bayeta Pagiza nueva: Una faja tejida blanca y azul, nueva: por cobija un pedazo de Noviciate, servido: y una moña de Noviciate de mediada, con una vara de liston encarnado: y por dije una Cruz de metal dorado pequeña de Carabaca, pendiente de media vara de medio liston encarnado: y en este dia se Baptizò en el Sagrario con el nombre de Francisco Javier. Su fee (sic), en el Legajo n. ${ }^{0} 306^{46}$.

42. "Holán/Holán Batista. Sinónimo de Holanda y Cambray. Tela de lino (o algodón) blanca. Término procedente del lugar donde se inventó, identificando a los lienzos flamencos más conocidos. Holanda/Media Holanda/Holandeta/Holandilla. Tela de lienzo blanca muy fina y compacta, usada para camisas de la gente principal y después para sábanas, enaguas, etc., llamada así por fabricarse en Holanda, Frisia y otros parajes de las Provincias Unidas (“de procedencia flamenca” ...)”. M. García Fernández (2004), 115-145.

43. "BAyetA. s. f. Tela de lana mui floxa y rala, de ancho de dos varas lo mas regular, que sirve para vestídos largos de Eclesiásticos, mantillas de mugéres, y otros usos. Háilas de todas colóres, blancas, verdes, negras, \&c. Lat. Laneus pannus crispatus, cirratus. PRAGM. DE TASS. año 1680. fol. 4. Cada vara de bayéta contrahecha de Segobia veinte y cinco reales. QUEV. Tacañ. cap. 14. A las doce y media entró por la puerta una estantígua vestida de bayéta hasta los piés". Diccionario de Autoridades (1726), 581.

44. Cregüela: s. f. d. de CREA. Telae lineae genus; NTLlE RAE U 1780, p. 289,3. CREA: s. f. Lienzo entrefino bastante usado, Lintei genus. NTLLE. RAE U 1780, p. 289,1. En cambio, con referencia a la palabra CreA, el Diccionario de Autoridades es mucho más explícito, ya que en el tomo II (1729), encontramos: CREA. s. f. Cierto género de tela o lienzo, que no es de los más finos ni de los más toscos, que sirve para hacer camísas, sábanas y otras cosas. Llámase comunmente Leona, porque viene de León de Fráncia. Latín. Linea tela sic vulgò nominata. PRAGM. DE TASS. año 1680. fol. 8. La vara de crea leona entreancha, a quatro reales y medio. La de crea angosta, a tres reales y medio.

45. E. Gómez Martínez (1987), 65-66.

46. ADPM, L. 0017, fol. 8r, mat. 306. 
Después que el infante era depositado en el torno, lo recogía el ama de guardia y se lo entregaba al ama mayor que lo presentaba al rector tal y como había sido abandonado, para que realizase la correspondiente inscripción en el Libro de Matrículas. El siguiente paso sería el bautismo, no siendo arriesgado afirmar que no se le examinaba hasta después de haberlo cristianado, ya que hemos encontrado una matrícula en la que fue inscrito como "Teresa Josepha Augustina" y posteriormente la siguiente anotación: "Se equibocaron la Ama porque era varon y se llama Joseph Augustin" 4 .

Con respecto al nombre de los infantes se evidencia la influencia del santoral, ya que, si llegaban acompañados de una cédula en la que este se indicaba, la petición era respetada, en caso contrario se les asignaba el del santo del día o el del más relevante del mes, como es posible comprobar en los Libros de Matrículas. En cuanto al apellido, no es posible asegurar el que se les imponía, ya que, en los libros bautismales de la parroquia del Sagrario, a la que se llevaban para su bautismo, aparecen inscritos de la siguiente manera: nombre "de la Cuna" ${ }^{48}$. Sin embargo, en los asientos de las escrituras de prohijación aparecen anotados con el nombre y a continuación "Expósito-a", lo que nos lleva a pensar que este es el apellido ${ }^{49}$

Tras estos trámites, el menor era confiado a una de las amas de cría internas hasta la asignación de una externa ${ }^{50}$, de quien dependía la vida del expósito ya que era la primera persona que se encargaba directamente del infante. Las internas o cuneras estaban bajo la supervisión del ama mayor, la responsable de que cada una no criara a más de dos niños, algo no siempre posible debido a la cantidad de las exposiciones, y también vigilaba su alimentación y reposo para garantizar la calidad de la leche. Antes de su ingreso y después, cada quince días, se las reconocía para comprobar que estaban en condiciones para amamantarlos ${ }^{51}$. Obviamente a las externas no se les realizaba tanto control, valiéndose de múltiples artimañas para aparentar un buen estado de crianza, como, por ejemplo, darles a beber mucha agua para que empaparan los pañales cuando iban a reconocerlos ${ }^{52}$.

47. ADPM, L. 0016, fol. 186v, mat. 192.

48. Archivo Histórico Diocesano de Málaga (AHDM), Sección I, leg. 489, pieza (p.) 2.

49. Ello se puede comprobar en Archivo Histórico Provincial de Málaga (AHPM), Protocolos Notariales, Escribanía de José Anastasio de Zistos, 7 septiembre 1759, leg. 2996, fols. 143r-143v.; 9 abril 1760, fols. 307r-307v.; 15 enero 1766, leg. 2998, fols. 8r-8v.; 20 marzo 1766, fols. 61r-61v.

50. M. del P. de la Fuente Galán (1999), 123-124.

51. L. C. Álvarez Santaló (1980), 125.

52. M. Vallecillo Capilla (1990), 72-73. 
A lo largo del siglo XVIII comenzaron los primeros intentos de alimentación artificial y, aunque las inclusas fueron muy reticentes a ella, poco a poco fueron adoptándola y alimentando a los niños con "brebajes, como las sopas de vino o los batidos con manteca de vaca" ${ }^{53}$.

En los casos en los que el expósito sobrevivía al destete, que duraba año y medio aproximadamente, permanecía en la casa del ama hasta los tres años, cuando debía volver a la Cuna para su educación ${ }^{54}$. Sin embargo, a veces esta solicitaba su prohijamiento alegando el cariño que le había tomado, aunque también podría ser factible que fuera la madre, quien encontrándose en estado de extrema pobreza lo hubiera dejado en la inclusa con la intención de requerir su crianza a cambio de una remuneración, garantizando de esta manera su supervivencia ${ }^{55}$.

En el siglo XVII se promulgaron dos leyes que dictaminaron la educación y destino de los infantes, la primera por Felipe IV el 10 de febrero de 1623, donde se prohibían los estudios de Gramática en las casas de expósitos y se mandaba que fueran instruidos en el ejercicio de la Marina con el fin de ser útiles a la Corona; y la segunda, por la reina gobernadora el 22 de diciembre de 1677, insistiendo en su adiestramiento en dicho ejercicio ${ }^{56}$.

Como ya se ha comentado fue a lo largo del Siglo de las Luces cuando surgió un mayor interés hacia estos menores con la consiguiente proclamación de leyes destinadas a la crianza y educación de ellos:

Todos los niños se aplicarán a la escuela de primeras letras que por punto general deberá haber en los hospicios, para que sean instruidos en ellos de la doctrina cristiana poniendo en ello el mayor esmero (...) que los niños sean instruidos en las básicas disciplinas de leer, escribir y contar. Una vez que han adquirido estos básicos, (...) precedido de examen doméstico se explorará su voluntad y la de sus padres, si los tuvieren, para saber a qué oficio o arte de los que haya en dichos hospicios muestran inclinación, y tienen proporción por su talento, edad y fuerzas ${ }^{57}$.

Las expósitas recibían un trato distinto respecto a su aprendizaje, aunque en un principio se les daba una formación básica y religiosa similar, no se les ofrecía la posibilidad de adquirir ningún tipo de oficio que no se

53. Ibidem, 17.

54. M. Fernández Ugarte (1988), 111.

55. M. LEÓN VEGAS (2017), 357.

56. E. Gómez Martínez (1987), 21-22.

57. J. L. Sevilla Bujalance (2001), 77-78. 
ejercitase dentro del hospicio. La principal tarea de las niñas era coser y, aquellas que demostraban habilidades especiales se dedicaban a los trabajos más primorosos como el bordado, encajes, etc.:

Será muy útil una extendida huerta, donde lo permita el clima, para proveer de vituallas la casa y para que las hospicianas, (...). Desde la más temprana edad se les instruirá en la doctrina cristiana leer y escribir por sus respectivos maestros; y a su proporcionado tiempo se les irá instruyendo en los primeros elementos o principio de las labores propias de su sexo, que son facer faxa y media ${ }^{58}$.

Estas normativas establecían la obligación de instruirlos tanto en la religión católica como en los principios de la educación para luego formarlos en un oficio y que pudieran reintegrarse en la sociedad con el consiguiente beneficio para la nación, pues "la Real Cédula de 2 de septiembre de 1784 expresa claramente que no servirá de impedimento, para ejercer cualquier arte u oficio, la ilegitimidad" 59 .

Hay estudiosos que dicen que las innovaciones que se realizaron en el Siglo de las Luces respecto a los pobres eran debidas a los planteamientos filantrópicos de la época, pero estas afirmaciones solo tienen en cuenta las ideas utópicas y eluden el hecho de que a los gobernantes lo que les importaba era tener suficiente mano de obra para garantizar el desarrollo del país ${ }^{60}$, ejemplo de ello lo encontramos en las palabras de Campomanes:

... la España, escasa de población para llenar este vacío y completar toda la gente que necesita en el vasto espacio de la monarquía, debe aprovechar estas inocentes criaturas, porque así lo dicta la caridad y religión cristiana, y aconseja también la utilidad general del Estado. Como éste costea los alimentos y la educación de los expósitos, es dueño de darles la dirección y destino más conveniente ${ }^{61}$.

Además de acceder a la sociedad mediante la incorporación laboral también podían hacerlo a través de otros sistemas como la adopción o prohijamiento. Hemos de aclarar que no hacemos distinción entre estos términos porque en la época ambos significaban lo mismo, puesto que, si

58. Ibidem, 79-81.

59. M. Vallecillo Capilla (1990), 16.

60. M. Velázquez Martínez (1991), 75.

61. Ibidem, 167. 
accedemos a "la fuente jurídica originaria, las Partidas, consideran equivalente uno y otro término: Adoptio, en latin, tanto quier decir en romance, como porfijamiento" 62 . Y la recuperación por parte de sus parientes, quienes utilizaban los datos de la cédula con la que había sido abandonado, pasando automáticamente a formar parte de su entorno familiar ${ }^{63}$. Realmente esta última opción no fue tan habitual como podríamos pensar, ya que en muchas ocasiones la elevada tasa de mortalidad de los niños en sus primeros meses de vida impidió el reencuentro doméstico. Valga como ejemplo de esta situación la siguiente matrícula:

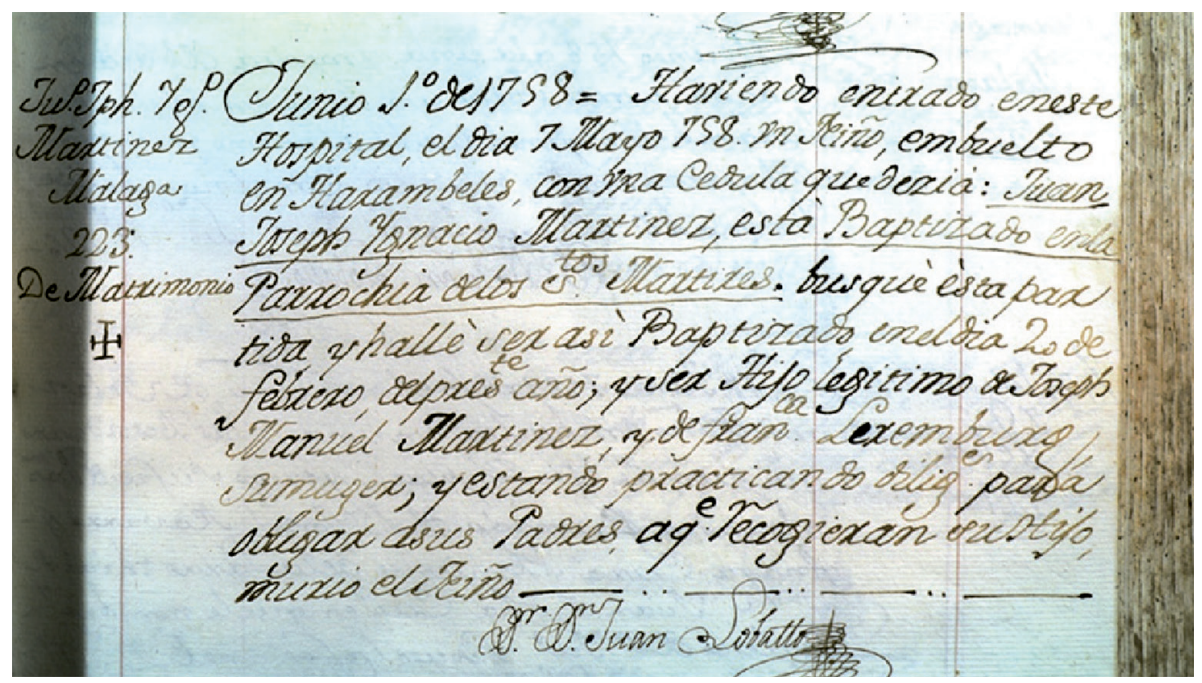

Imagen 5. Matrícula de niño legítimo de matrimonio que murió mientras se practicaban las diligencias para que lo recogiesen.

Fuente: ADPM, L. 0017, fol. 52r, mat. 223.

En cuanto a la adopción se podía producir por varios motivos, la compasión o cariño provocaba en este caso que a veces fuera aceptado como parte integrante de la familia, ya que se les asignaba una dote o incluso llegaba a ser heredero universal de los bienes del prohijador, como es posible comprobar en las escrituras de prohijación en protocolos notariales. Aunque en la mayoría de las ocasiones el prohijamiento se producía por provecho para el adoptante, en cuyo caso podía ser devuelto a la Cuna 
si no tenía las cualidades que este exigía o por otras cuestiones que no siempre se explicitaban, lo que nos lleva a apreciar al expósito como una mercancía. La siguiente matrícula, en que la niña es devuelta sin especificar el motivo, sirve para ejemplificar esta situación:

En 4 de Septiembre de 755 a las 8 de la noche pusieron en el torno una niña liada en unos jarambel de camisón hecho pedasos y un pedasillo de bayeta pagisa vieja y una mantilla de bayeta blanca por capa y en el dia siguiente se baptizo en el sagrario con los nombres de Rosalia Manuela fue su padrino Bartolome Harraez su fe legajo 9 W (sic) 129.

Y a continuación en el lado inferior izquierdo encontramos lo siguiente:

En 7 de Noviembre de 1755 se la llevó a criar de Grazia Doña Maria de Cordova mujer de Gregorio Muñoz tejedor calle de las Parras, folio 60 del segundo Libro de salida: la volvió y murió en el Hospital en 2 de Diziembre $1755^{64}$.

El prohijamiento o adopción se podía realizar por dos vías distintas: una ante escribano, que podríamos llamar legal y llevaba aparejada una dote, y otra que se hacía a través del rector o administrador de la casa que tenía menor valor jurídico, pero suponía igualmente la salida del niño de la institución. Había también dos fórmulas, en función de la edad del infante: si el prohijado se encontraba entre los siete y catorce años no se necesitaba su autorización, mientras que si tenía más de catorce años debía ser consultado $^{65}$. Estas edades eran importantes en la época que nos ocupa ya que el derecho canónico establecía como mínimo la edad de 12 años para las féminas y 14 para los varones para realizar los desposorios ya que "habían superado el elástico umbral de la edad de la razón, situado entre 7 y $12 "{ }^{\prime 66}$.

Para justificar la alta mortalidad de estos niños, tampoco es posible determinar una sola causa, tendríamos que achacarla a un conjunto de motivos, tales como el abandono y la pobreza, sumados a la mala alimentación. Se unirían a estos los escasos cuidados a los que estaban sometidos, sobre todo los que eran criados por amas externas, quienes, debido al bajo estipendio que cobraban, no atendían adecuadamente la crianza del menor lo que ocasionaba enfermedades y muerte. La atención médica dejaba mucho que desear, quizás porque a los facultativos no se les pagaba, ya que se

64. ADPM, L. 0016, fol. 175r, mat. 129.

65. A. Marchant Rivera (2009), 945.

66. M. García Fernández (2019), 39-43. 
pensaba que era un acto de misericordia. No debemos olvidar el concepto que la sociedad tenía de ellos, estas criaturas no eran dignas de cuidados pues eran consideradas fruto del pecado, negándose incluso algunos sacerdotes a cantarles en los entierros ${ }^{67}$.

A consecuencia de la elevada tasa de mortandad y la pésima situación en que se encontraban estos menores en Málaga, el obispo Manuel Antonio Ferrer y Figueredo, convocó a varias señoras con la intención de crear una agrupación, bajo su amparo, que se dedicase a inspeccionar la Casa-Cuna y el estado de los infantes, así como a vigilar la situación de aquellos que eran atendidos por amas externas. El 23 de noviembre de 1796 se aprobaron los estatutos de la agrupación que sería llamada "Asociación de Señoras para Exercitar la Caridad con los niños expósitos de Málaga y su partido", el reglamento fue ratificado por Carlos IV el día 4 de diciembre del mismo año, nombrando directora a la condesa de Guadiana; secretaria a Isabel de St. Maxent; consultor a Diego Benítez Chacón, figurando como protectores de la institución Carlos IV y el ya citado Ferrer y Figueredo ${ }^{68}$.

\section{EL VOLUMEN DE EXPÓSITOS: LAS MATRÍCULAS}

En nuestro estudio hemos analizado las matrículas de expósitos correspondientes a los quinquenios 1754-1758 y 1784-1788 para hacer una valoración general de la aplicación de la legislación ilustrada en Málaga. Se han hallado ciertas irregularidades entre 1756-1758, ya que en estos años no se registra en las matrículas el motivo de la partida de los menores, y no estando disponibles los Libros de Salida debido a su desaparición, hemos de indicar que los porcentajes aportados para las marchas de la Cuna, en estas fechas, son una aproximación.

Hecha esta aclaración podemos afirmar que durante el período 17541758, entraron en la Casa de Expósitos de Málaga un total de 865, siendo 422 varones y 443 féminas, de los cuales fallecieron 171 y 193 respectivamente, lo que lleva a un total de 364 difuntos arrojando un porcentaje del $42,08 \%$ del total de los ingresos ${ }^{69}$, correspondiendo un $19,77 \%$ a varones y un $22,31 \%$ a féminas. Llama la atención que el porcentaje de salidas por defunción, en este periodo, sea superior para las féminas, pero hemos de recordar la inexistencia de apuntes ya citada.

67. T. Gómez Ruiz (1997), 202-203.

68. E. J. Caro López (2015-2016), 86-88.

69. Todos los porcentajes se han redondeado a dos decimales. 
A pesar de su elevado nivel, debido a la falta de documentación mencionada pensamos que las cifras aportadas para las salidas de la institución por fallecimiento son más bajas que las reales, puesto que al analizar otras Cunas del territorio peninsular los porcentajes dados son más elevados por lo que traemos a colación los datos proporcionados por M. J. Pérez Álvarez para La Obra Pía de Nuestra Señora de la Blanca en la ciudad de León, que en el periodo de 1750-1759 arroja un 89,5\% de fallecimientos ${ }^{70}$, y los del Hospital Real y General de Nuestra Señora de Gracia, de Zaragoza, que para el siglo XVIII da un $75 \%$ de fallecidos sobre el total de los ingresos ${ }^{71}$.

Durante el mismo período, según la documentación manejada, fueron prohijados un total de 29 expósitos, siendo 10 de ellos niños y 19 niñas, una con una dote de 30 ducados, resultando un porcentaje del 3,35\% del total de los ingresos, mientras que los entregados a sus padres fueron $7 \mathrm{y}$ 3 respectivamente, es decir, el 1,16\% de las entradas en la inclusa.

Tabla 1. Salidas anuales de expósitos con respecto al total de ingresos: 1754-1758

\begin{tabular}{|c|c|c|c|c|c|}
\cline { 2 - 6 } \multicolumn{1}{c|}{} & INGRESOS & \multicolumn{4}{c|}{ SALIDAS } \\
\hline AÑOS & Totales & Fallecidos & Ent. a padres & Prohijados & Totales \\
\hline 1754 & 198 & 158 & 1 & 16 & 175 \\
\hline 1755 & 192 & 150 & 3 & 7 & 160 \\
\hline 1756 & 168 & 49 & 0 & 4 & 53 \\
\hline 1757 & 165 & 1 & 3 & 1 & 5 \\
\hline 1758 & 142 & 6 & 3 & 1 & 10 \\
\hline $1754-1758$ & 865 & 364 & 10 & 29 & 403 \\
\hline
\end{tabular}

Fuente: Elaboración propia a partir de los datos obtenidos en ADPM, Libros de Matrículas.

Debido a que en la provincia solo existían Casas de Expósitos en Málaga, Antequera y Ronda, a la capital llegaban niños de casi todos los pueblos y para este período suman un total de 252 expósitos, lo que lleva a un porcentaje del 29,13\% de los ingresos. Destaca Vélez-Málaga, con un total de 100 expósitos, arrojando un 39,68\% de estas incorporaciones y un $11,56 \%$ del total para 1754-1758. A través del hospital de Vélez-Málaga llegaban procedentes de Sedella, Nerja, Benamocarra, Competa, Torre del

71. F. J. Alfaro Pérez y J. A. Salas Auséns (2001), 13. 
Mar, Frigiliana, es decir, todos los que pertenecían a la Axarquía, donde eran atendidos hasta que se procedía a su traslado a Málaga, pese a lo cual son individualizados en las inscripciones y también en nuestras tablas, a pesar de ser de la tierra de Vélez. También se ha observado que a partir de 1758 llegaron a la inclusa menores desde Estepona debido a que en dicho año se firmó un auto judicial para que los procedentes de la villa fuesen trasladados a la Casa de Expósitos de la capital ${ }^{72}$.

Tabla 2. Expósitos procedentes de los pueblos de la provincia: 1754-1758

\begin{tabular}{|c|c|c|c|c|c|}
\hline & \multicolumn{5}{|c|}{ AÑOS } \\
\hline PUEBLOS & 1754 & 1755 & 1756 & 1757 & 1758 \\
\hline Algarrobo & 0 & 0 & 0 & 1 & 0 \\
\hline Alhaurín el Grande & 7 & 5 & 1 & 1 & 4 \\
\hline Alhaurín de la Torre & 0 & 0 & 1 & 0 & 1 \\
\hline Álora & 1 & 3 & 0 & 0 & 0 \\
\hline Alozaina & 2 & 2 & 0 & 0 & 0 \\
\hline El Borge & 1 & 0 & 0 & 1 & 1 \\
\hline Canillas de Albaidas & 1 & 0 & 0 & 0 & 0 \\
\hline Casabermeja & 0 & 0 & 0 & 1 & 0 \\
\hline Casarabonela & 1 & 0 & 1 & 1 & 1 \\
\hline Colmenar & 0 & 2 & 0 & 1 & 0 \\
\hline Coín & 8 & 8 & 7 & 5 & 4 \\
\hline Cómpeta & 1 & 0 & 1 & 1 & 1 \\
\hline Churriana & 0 & 0 & 0 & 0 & 1 \\
\hline Estepona & 0 & 0 & 0 & 0 & 1 \\
\hline Guaro & 0 & 1 & 1 & 0 & 0 \\
\hline Marbella & 1 & 4 & 7 & 4 & 6 \\
\hline Melilla & 0 & 0 & 1 & 0 & 1 \\
\hline Mijas & 1 & 1 & 5 & 1 & 1 \\
\hline Moclinejo & 1 & 0 & 0 & 0 & 0 \\
\hline Monda & 2 & 1 & 1 & 1 & 0 \\
\hline Ojén & 3 & 2 & 3 & 0 & 2 \\
\hline
\end{tabular}

72. ADPM, L. 0017, fol. 59r.

(C) Baetica. Estudios Historia Moderna y Contemporánea, 39, 2019, 219-250. Facultad de Filosofia y Letras, Universidad de Málaga. Departamento de Historia Moderna y Contemporánea 


\begin{tabular}{|c|c|c|c|c|c|}
\hline \multirow[b]{2}{*}{ PUEBLOS } & \multicolumn{5}{|c|}{ AÑOS } \\
\hline & 1754 & 1755 & 1756 & 1757 & 1758 \\
\hline Pizarra & 0 & 1 & 0 & 0 & 0 \\
\hline Riogordo & 0 & 1 & 0 & 1 & 0 \\
\hline Sedella & 3 & 0 & 0 & 1 & 0 \\
\hline Tolox & 3 & 1 & 1 & 2 & 0 \\
\hline Torre del Mar & 0 & 0 & 0 & 0 & 1 \\
\hline Totalán & 1 & 1 & 0 & 0 & 1 \\
\hline Vélez-Málaga & 20 & 20 & 20 & 24 & 16 \\
\hline Ventas de Bizmiliana & 0 & 0 & 1 & 0 & 0 \\
\hline Yunquera & 0 & 0 & 0 & 1 & 1 \\
\hline TOTAL & 57 & 53 & 52 & 47 & 43 \\
\hline
\end{tabular}

Fuente: Elaboración propia a partir de los datos obtenidos en ADPM, Libros de Matrículas.

Dando un salto en el tiempo, para comprobar si las normativas y leyes dictadas por Carlos III mejoraron la situación de los expósitos, pasamos a analizar el período 1784-1788. En estos años fueron acogidos en la casa un total de 1077, siendo 589 de ellos niños y 488 niñas, falleciendo 765, 438 y 327 respectivamente, lo que arroja un $71,03 \%$ de difuntos sobre el total de ingresos, según géneros un 57,25\% para ellos y un 42,75 \% para ellas.

Los menores prohijados en esta etapa suman un total de 109, de los cuales 54 son niños y 55 niñas lo que lleva a un 10,12 \% del total de los que un $5,01 \%$ correspondieron a varones y un 5,10 \% a féminas, habiéndose hallado 45 casos con dotes distribuidas de la siguiente manera:

Tabla 3. Número de prohijamientos con dote para el período 1784-1788

\begin{tabular}{|c|c|c|c|c|c|c|c|c|c|c|}
\cline { 2 - 12 } \multicolumn{1}{c|}{} & \multicolumn{10}{c|}{ CANTIDAD DE LA DOTE EN DUCADOS } \\
\hline AÑ OS & $\mathbf{1 0}$ & $\mathbf{2 0}$ & $\mathbf{2 5}$ & $\mathbf{3 0}$ & $\mathbf{4 0}$ & $\mathbf{5 0}$ & $\mathbf{6 0}$ & $\mathbf{1 0 0}$ & $\mathbf{2 0 0}$ & Total \\
\hline 1784 & 1 & 0 & 0 & 0 & 1 & 0 & 0 & 0 & 0 & 2 \\
\hline 1785 & 0 & 1 & 0 & 1 & 0 & 1 & 0 & 0 & 0 & 3 \\
\hline 1786 & 0 & 3 & 0 & 0 & 0 & 1 & 0 & 0 & 0 & 4 \\
\hline 1787 & 0 & 8 & 1 & 6 & 0 & 1 & 0 & 0 & 0 & 16 \\
\hline 1788 & 0 & 11 & 0 & 4 & 0 & 1 & 1 & 2 & 1 & 20 \\
\hline $1784-1788$ & 1 & 23 & 1 & 11 & 1 & 4 & 1 & 2 & 1 & 45 \\
\hline
\end{tabular}

Fuente: Elaboración propia a partir de los datos obtenidos en ADPM, Libros de Matrículas. 
Respecto a los entregados a sus padres se han contabilizado 61, 32 y 29 en cada caso, un 5,66\% con respecto al total de ingresados en este quinquenio, correspondiendo el $2,97 \%$ a infantes y el $2,69 \%$ a infantas.

Tabla 4. Salidas anuales de expósitos con respecto al total de ingresos: 1784-1788

\begin{tabular}{|c|c|c|c|c|c|}
\cline { 2 - 6 } \multicolumn{1}{c|}{} & INGRESOS & \multicolumn{4}{c|}{ SALIDAS } \\
\hline AÑNS & Totales & Fallecidos & Ent. padres & Prohijados & Totales \\
\hline 1784 & 233 & 141 & 5 & 19 & 165 \\
\hline 1785 & 216 & 146 & 9 & 9 & 164 \\
\hline 1786 & 227 & 170 & 14 & 27 & 211 \\
\hline 1787 & 192 & 143 & 19 & 29 & 191 \\
\hline 1788 & 209 & 165 & 14 & 25 & 204 \\
\hline $1784-1788$ & 1077 & 765 & 61 & 109 & 935 \\
\hline
\end{tabular}

Fuente: Elaboración propia a partir de los datos obtenidos en ADPM, Libros de Matrículas.

En el período de 1784-1788 también observamos ciertas irregularidades puesto que en algunas matrículas de los años 1784-1785 hallamos anotaciones de este tipo: salió, la fecha de la salida, el número de folio y una "P", que no sabemos exactamente su significado. Por esta incertidumbre, han sido contabilizadas aparte, siendo en total 47 de las cuales 22 pertenecen a niños y 25 a niñas, lo que se traduce en un $4,36 \%$ del total de ingresos.

Igualmente hemos procedido con aquellas cuya apostilla es la siguiente: "se quedó o quedan con él/ella", lo que hace sospechar que es el ama de cría quien lo reclama, siendo concretamente 19 niños y 14 niñas, suponiendo el $3,06 \%$ de los expuestos durante el último quinquenio del reinado de Carlos III. También se han descubierto dos registros uno de 1786 y otro de 1787 , con la siguiente anotación "lo/a ocultaron" "73, es decir, que una vez que estos niños salieron de la institución fue imposible encontrar su paradero.

Con respecto a los oriundos de los pueblos suman un total de 335 , el $31,10 \%$ del total de los ingresos. También en este quinquenio sobresale Vélez-Málaga con 140, correspondiendo al 41,79\% de los procedentes de la provincia y al $12,99 \%$ del total de los ingresados en el quinquenio de 1784-1788.

73. ADPM, L. 0019, fols. 144r y 166r.

(C) Baetica. Estudios Historia Moderna y Contemporánea, 39, 2019, 219-250. Facultad de Filosofia y Letras, Universidad de Málaga. Departamento de Historia Moderna y Contemporánea 
Tabla 5. Expósitos procedentes de los pueblos de la provincia: 1784-1788

\begin{tabular}{|c|c|c|c|c|c|}
\hline \multirow[b]{2}{*}{ PUEBLOS } & \multicolumn{5}{|c|}{ AÑOS } \\
\hline & 1784 & 1785 & 1786 & 1787 & 1788 \\
\hline Algarrobo & 0 & 1 & 0 & 1 & 0 \\
\hline Alhaurín el Grande & 2 & 1 & 2 & 1 & 4 \\
\hline Alhaurín de la Torre & 0 & 0 & 0 & 1 & 0 \\
\hline Almáchar & 1 & 0 & 1 & 1 & 1 \\
\hline Álora & 1 & 0 & 3 & 1 & 2 \\
\hline Alozaina & 2 & 3 & 1 & 1 & 3 \\
\hline Benamocarra & 1 & 0 & 0 & 0 & 0 \\
\hline El Borge & 1 & 1 & 0 & 0 & 0 \\
\hline El Burgo & 1 & 0 & 0 & 0 & 0 \\
\hline Canillas de Aceituno & 0 & 0 & 0 & 1 & 0 \\
\hline Canillas de Albaidas & 0 & 0 & 0 & 0 & 1 \\
\hline Cártama & 1 & 5 & 3 & 0 & 0 \\
\hline Casabermeja & 0 & 0 & 1 & 0 & 0 \\
\hline Casarabonela & 0 & 2 & 0 & 3 & 1 \\
\hline Colmenar & 1 & 3 & 0 & 0 & 2 \\
\hline Churriana & 1 & 4 & 0 & 1 & 0 \\
\hline Cómpeta & 0 & 0 & 0 & 0 & 0 \\
\hline Coín & 6 & 5 & 2 & 5 & 7 \\
\hline Estepona & 1 & 4 & 6 & 3 & 1 \\
\hline Frigiliana & 2 & 1 & 1 & 0 & 0 \\
\hline Guaro & 0 & 1 & 0 & 0 & 0 \\
\hline Macharaviaya & 0 & 0 & 0 & 0 & 1 \\
\hline Marbella & 13 & 7 & 5 & 4 & 4 \\
\hline Mijas & 3 & 1 & 2 & 2 & 2 \\
\hline Moclinejo & 0 & 0 & 0 & 0 & 1 \\
\hline
\end{tabular}




\begin{tabular}{|l|c|c|c|c|c|}
\cline { 2 - 7 } \multicolumn{1}{c|}{} & \multicolumn{5}{c|}{ AÑOS } \\
\hline PUEBLOS & $\mathbf{1 7 8 4}$ & $\mathbf{1 7 8 5}$ & $\mathbf{1 7 8 6}$ & $\mathbf{1 7 8 7}$ & $\mathbf{1 7 8 8}$ \\
\hline Monda & 0 & 2 & 1 & 0 & 3 \\
\hline Nerja & 1 & 1 & 4 & 3 & 3 \\
\hline Ojén & 2 & 3 & 2 & 0 & 1 \\
\hline Periana & 0 & 0 & 0 & 0 & 1 \\
\hline Pizarra & 0 & 1 & 0 & 1 & 0 \\
\hline Tolox & 1 & 1 & 1 & 1 & 0 \\
\hline Torrox & 1 & 1 & 0 & 0 & 0 \\
\hline Totalán & 1 & 0 & 0 & 0 & 0 \\
\hline Vélez-Málaga & 32 & 26 & 29 & 26 & 27 \\
\hline Yunquera & 0 & 1 & 0 & 0 & 0 \\
\hline & 75 & 75 & 64 & 56 & 65 \\
\hline
\end{tabular}

Fuente: Elaboración propia a partir de los datos obtenidos en ADPM, Libros de Matrículas.

Como se ha podido comprobar, a la Casa-Cuna de Málaga llegaba una cantidad bastante importante de infantes desde todos los puntos de la provincia, destacando Vélez-Málaga, motivo por el cual en 1790 el obispo Manuel Antonio Ferrer y Figueredo en respuesta a la encuesta que mandó realizar Carlos IV para conocer el estado en que se encontraban las inclusas, informó al Consejo de Castilla que en la diócesis sólo había tres centros destinados al cuidado de los expósitos y que en ellos los niños se encontraban en una situación deplorable, manifestando expresamente "la necesidad de crear inclusas en las ciudades de Vélez, Marbella y Coín y en las villas de Grazalema y Archidona. En la cuna de Málaga mueren 992 criaturas de las 1301 que ingresan en el quinquenio 1786-1790, el 76,02 por cien" 74 .

Para poder hacernos una idea de la magnitud del fenómeno en Málaga, se ha accedido a los censos demográficos de Aranda y Floridablanca ya que ellos nos aportan el porcentaje de menores de 7 años en la época. Si bien hemos de aclarar que el primero ha sido tachado de inverosímil, 
aunque el Instituto Nacional de Estadística lo circunscribe dentro de los modernos, dado que la información es recogida individualmente y no por familias ${ }^{75}$.

El Censo de Aranda nos arroja una población total para la ciudad de 41692 habitantes en el 1769, de los que 5471 son menores de siete años, es decir, el 13,12\%, siendo 3695 son varones y 1776 féminas, lo que nos lleva a un $67,53 \%$ para los primeros y un $32,46 \%$ para las segundas del total de menores.

Floridablanca aporta una totalidad de 49136 vecinos para 1787, correspondiendo 7648 a menores de 7 años, lo que origina un 15,57\%, diferenciados por sexo son 3890 niños y 3758 niñas, cifras que llevan a un $50,86 \%$ de varones y a un 49,14\%.

Las cifras que manejamos para el segundo censo son 1077 ingresos en la Cuna, lo que da un 14,08 \% de ingresos de expósitos del total de menores de siete años y el 2,19 \% de la población malacitana.

\section{CONCLUSIONES}

De lo expuesto anteriormente es posible afirmar que la legislación promulgada por Carlos III dirigida hacia este colectivo supuso una novedad, puesto que atendía a la crianza y educación de los infantes con el fin de su reincorporación en la sociedad y no solo a su recogida como lo hacían las leyes anteriormente dictadas. A pesar de ello, no surtieron el efecto deseado en ese momento, aunque no descartamos que lo hicieran a mayor largo plazo, de ahí la necesidad de continuar con esta investigación para el reinado de Carlos IV.

El fenómeno de la exposición en Málaga en el siglo XVIII, al igual que en el resto de las ciudades del país, fue una práctica habitual, porque solucionaba la deshonra de la familia y a la vez daba al menor una oportunidad de supervivencia.

La situación del menor que había sido recuperado era totalmente distinta a la del adoptado, porque el prohijado abandonaba la Casa-Cuna, pero no perdería nunca la mácula de expósito, ya que el prohijamiento o adopción le garantizaba un porvenir y sustento, pero la mayoría de las veces no le transmitía el apellido y, por ende, la situación social del adoptante.

A través del estudio de las matrículas y las cédulas que portaban los expósitos, se vislumbra la coyuntura familiar del menor y los motivos que 
llevaron a su abandono y, comprobado el vacío historiográfico sobre la Casa de Expósitos de Málaga y las fuentes documentales conservadas, se pretende continuar con los estudios de la referida institución ya que ello llevaría a un mejor entendimiento del pensamiento ilustrado y se daría luz a un aspecto que es considerado fundamental para la sociedad de la época moderna.

Para finalizar, debemos afirmar que en el Antiguo Régimen era mucho más importante conservar la honra que la vida de un menor, el cual desde el momento en que fue concebido estaba destinado a la muerte, o en el mejor de los casos a vivir dentro de una sociedad que lo rechazaba, por el simple hecho de no haber nacido dentro de una familia bendecida con el sacramento del santo matrimonio.

\section{BIBLIOGRAFÍA}

Alcubierre Moya, Beatriz (2018), Niños de nadie. Usos de la infancia menesterosa en el contexto borbónico, Universidad Autónoma del Estado de Morelos, México.

Alfaro Pérez, Francisco José y Salas Auséns, José Antonio (2001), "Inserción social de los expósitos del Hospital de Gracia de Zaragoza", Obradoiro Historia Moderna, 10, pp.11-27.

Alvar Ezquerra, Alfredo y Domínguez Ortiz, Antonio (2005), Historia de España XIII. La sociedad española en la Edad Moderna, Istmo, Madrid.

Álvarez Santaló, León Carlos (1977), "La Casa de Expósitos de Sevilla en el siglo XVII", Cuadernos de Historia del Instituto Jerónimo Zurita, VII, pp. 491-532.

- (1978), "Un ensayo metodológico: posibilidades de evaluación del nivel de ilegitimidad de los expósitos a través de la valoración de su ajuar como exponente del grupo social de procedencia", Actas del I Congreso de Historia de Andalucía, Andalucía Moderna, vol. III, Junta de Andalucía, Córdoba, pp. 61-71.

- (1980), Marginación social y mentalidad en Andalucía Occidental: Expósitos de Sevilla (1613-1910), Consejería de Cultura de la Junta de Andalucía, Sevilla.

Blanco Carrasco, José Pablo; García Fernández, Máximo y Olival, Fernanda (coords) (2019), Jóvenes y juventud en los espacios ibéricos durante el Antiguo Régimen. Vidas en construcción, Colibrí, Lisboa.

CARo López, Eduardo José (2015-2016), "El arzobispo obispo Ferrer y Figueredo y la asociación de señoras para exercitar la caridad (1796)", Isla de Arriarán, XLII-XLIII, pp. 67-93.

Cava López, M. ${ }^{a}$ Gema (2000), Infancia y Sociedad en la Alta Extremadura durante el Antiguo Régimen, Institución Cultural "El Brocense" y Diputación Provincial, Cáceres. 
- (2004), "Niños e Infancia en la investigación sobre la Edad Moderna: el abandono de una historia de abandonados", en A. Alvar Ezquerra, J. CONTRERAS CONTRERAS y J. I. Ruiz Rodríguez (eds.), Política y cultura en la época moderna. (Cambios dinásticos. Milenarismos, mesianismos y utopías), Universidad, Alcalá de Henares, pp. 751-761.

Chacón, Francisco; Fresneda, Rafael y Elgarrista, Rosa (1986), "El ciclo de la muerte: estudio de los factores de mortalidad en los niños expósitos durante el primer mes (Murcia 1650-1721)", en Actas del VIII Congreso Nacional de Historia de la Medicina, III, Murcia-Cartagena, pp. 924-938.

Cobo Barquín, Juan Carlos, Hernández Mejía, Radhamés y SÁnchez Fernández, Luis Vicente (2013), "Marginación y pobreza desde la cuna: el niño expósito en el Concejo de Siero, Asturias (1800-1936)", Revista de Demografía Histórica, XXXI, (II), pp. 131-165.

Conde de Cabarrús (1820), Cartas del conde de Cabarrús al señor don Gaspar de Jovellanos, sobre los obstáculos que la naturaleza, la opinión y las leyes a la felicidad pública, impreso por Lawalle joven y sobrino, Burdeos.

Demerson, Paula de (1972), "La Real Inclusa de Madrid a finales del siglo XVIII", Anales del Instituto de Estudios Madrileños, VIII, pp. 261-272.

[Diccionario de Autoridades] Diccionario de la lengua castellana, en que se explica el verdadero sentido de las voces, su naturaleza y calidad, con las phrases o modos de hablar, los proverbios o refranes, y otras cosas convenientes al uso de la lengua, 6 tomos, Real Academia Española, Madrid, 1726-1739.

Domínguez Ortiz, Antonio (1983), "Los Expósitos en la España Moderna: la obra de Antonio Bilbao", en A. Romero Redondo, Les problemes de l'exclusion en Espagne (XVI-XVII siècles), Univeristé de Paris-Sorbonne, París, pp. 167-176.

Eiras Roel, Antonio (1967), "La Casa de expósitos del Real Hospital de Santiago en el siglo XVIII", Boletín de la Universidad Compostelana, 75-76, pp. 295-355.

Fernández Ugarte, María (1988), Expósitos en Salamanca a comienzos del siglo XVIII, Diputación Provincial, Salamanca.

Fuente Galán, M. del Prado de la (1997), "La situación de las inclusas en el siglo XVIII. La Encuesta de 1790", Chronica Nova, 24, pp. 71-78.

- (1999), “Una institución para los niños expósitos de Granada: La creación de la Casa-Cuna (siglos XVI-XVIII)", Boletín de la Asociación de Demografía Histórica, XVII (I) pp. 115-130.

García de la LeÑa, Cecilio (1793), Conversaciones Históricas Malagueñas, Descanso VI, impreso por Luis de Carreras, Málaga.

García Fernández, Máximo (2004), “Tejidos con 'denominación de origen extranjera' en el vestido castellano. 1500-1860", Estudios Humanísticos. Historia, 3, pp. 115-145.

- (2019), Los caminos de la juventud en la Castilla Moderna. Menores, huérfanos y tutores, Madrid, Sílex. 
García GonzÁlez, Francisco (2007), "La edad y el curso de la vida. El estudio de las trayectorias vitales y familiares como espejo social del pasado", en F. Chacón Jiménez, J. Hernández Franco y F. García González (eds.), Familia y organización social en Europa y América, siglos $X V$ - $X X$, Editum, Murcia, pp. 89-108.

Gómez Martínez, Enrique (1987), Los Niños Expósitos en Andújar, Universidad, Córdoba.

Gómez Ruiz, Trino (1997), El Hospital Real de Santa María Magdalena y la Casa de Expósitos de Almería, Instituto de Estudios Almerienses y Diputación Provincial, Almería.

Hidalgo Fernández, Francisco (2019), "Más allá del literato. La familia a través de una trayectoria vital: el platero Nicolás Miguel Fernández de Moratín (1738-1809)", en P. Ortega del Cerro y A. Irigoyen López (coords.), Profesiones, ciclos vitales y trayectorias familiares entre la continuidad y la transformación (siglos XVII-XX), Editum, Murcia, pp. 143-163.

LEÓn Vegas, Milagros (2013), "La "protección social” en la Edad Moderna: cofradías y fundaciones pías en el sur peninsular (siglo XVI)", Baetica. Estudios de Arte, Geografía e Historia, 35, pp. 283-297.

- (2017), "La adopción de expósitos a través de los fondos notariales. La Casa Cuna de Antequera (1667-1800)", en F. Henarejos López y A. Irigoyen López (eds.), Escenarios de familia: trayectorias, estrategias y pautas culturales, siglos XVI-XX, Universidad, Murcia, pp. 355-366.

Marchant Rivera, Alicia (2009), "La tutela, el prohijamiento y la carta de aprendiz: instrumentos para la historia de la situación del menor en Málaga durante la primera mitad del siglo XVI", en J. J. Bravo Caro y J. Sanz Sampelayo (coords.), Población y grupos sociales en el Antiguo Régimen. Actas de la IX Reunión Científica de la Fundación Española de Historia Moderna, vol. II, Área de Historia Moderna de la Universidad, Málaga, pp. 943-957.

Medina Plana, Raquel (2014), "Escrituras de adopción o prohijamiento de expósitos de la Inclusa de Madrid (1700-1852)", Cuadernos de Historia del Derecho, 21, pp. 189-211.

Novísima Recopilación de las Leyes de España (1805), tomo III, libro VII, título XXXVIII "De los hospitales, hospicios y otras casas de misericordia", ley IV, Madrid.

Pérez Álvarez, María José (2008), “La exposición en la ciudad de León: La Obra Pía Nuestra Señora la Blanca (1700-1791)", Revista de Historia Moderna, 26, pp. 343-367.

Pérez Moreda, Vicente y Aldea Vaquero, Quintín (2005), "Discurso leído el día 8 de mayo de 2005 en la recepción pública del Excmo. Sr. Don Vicente Pérez Moreda y contestación por el Excmo. Sr. Don Quintín Aldea Vaquero", La infancia abandonada en España (siglos XVI-XX), Real Academia de la Historia, Madrid. 
Reder Gadow, Marion (1985), "Una institución docente malagueña del siglo XVIII: Los Niños de la Providencia”, Baetica. Estudios de Arte, Geografía e Historia, 8, pp. 405-415.

Sanchidrián Blanco, Carmen y Martín ZúÑiga, Francisco (2009), "Protección y reeducación de la infancia abandonada: La Casa de la Misericordia de Málaga (1862-1936)", Bordón, 61 (4), pp. 123-140.

Santana Pérez, Juan Manuel (1993), Cunas de Expósitos y Hospicios en Canarias (1700-1837), Ediciones del Cabildo Insular de Gran Canaria, Las Palmas de Gran Canaria.

- (1996), "Sobre el encierro de los pobres en los tiempos modernos", Espacio, Tiempo y Forma. Serie IV, Historia Moderna, 9, pp. 339-357.

- (2000), "El mundo de la infancia en Fuerteventura y Lanzarote en el siglo XVIII", Tebeto. Anuario del Archivo Histórico Insular de Fuerteventura, 13, pp. 33-47.

Sevilla Bujalance, Juan Luis (2001), Los niños expósitos y desamparados en nuestro Derecho histórico, Universidad, Córdoba.

TArifa Fernández, Adela (1994), Pobreza y asistencia social en la España moderna. La Cofradía de San José y Niños Expósitos de Úbeda (siglos XVII y XVIII), Diputación Provincial, Jaén.

Vallecillo Capilla, Manuel (1990), Politica demográfica y realidad social en la España de la Ilustración. La situación del niño expósito en Granada (1753-1814), Universidad, Granada.

VelázQuez Martínez, Matías (1991), Desigualdad, indigencia y marginación social en la España Ilustrada. Las cinco clases de pobres de Pedro Rodríguez Campomanes, Universidad, Murcia.

Villas Tinoco, Siro (1982), Los gremios malagueños, Universidad, Málaga.

Zavala, Iris M. (1978), Clandestinidad y libertinaje erudito en los albores del siglo XVIII, Ariel, Barcelona. 